\title{
Effects of an animated diagram and video-based online breathing program for dyspnea in patients with stable COPD
}

This article was published in the following Dove Press journal:

Patient Preference and Adherence

6 September 2013

Number of times this article has been viewed

\author{
Fengping Liu' \\ Hongxing Cai \\ Qichun Tang ${ }^{2}$ \\ Yeqing Zou' \\ Hui Wang' \\ Zhiping $\mathrm{Xu}^{\prime}$ \\ Zhiming Wei' \\ Wei Wang' \\ Jiajia Cui' \\ 'Yancheng Medical College, \\ ${ }^{2}$ No I Yancheng Hospital, Jiangsu, \\ People's Republic of China
}

Correspondence: Fengping Liu Yancheng Medical College, 263 Jiefang

South Road, Yancheng, Jiangsu Province

224005, People's Republic of China

$\mathrm{Tel}+8613401780997$

Fax +8605I5 88I5 9499

Email liulaoshiyc@163.com
Background: Breathing programs have been reported to have positive effects in alleviating symptoms and optimizing pulmonary function in patients with chronic obstructive pulmonary disease (COPD). However, patients with stable disease may drop out of such programs if they are not modified to the individual's exercise tolerance level, or if they are not easy to perform in the home. Little is known about the effectiveness of web-based home breathing programs for dyspnea. The purpose of this study was to evaluate the effectiveness of an online breathing program which included an animated diagram and video-guided instruction on pulmonary function, exercise capacity, and health-related quality of life in patients with COPD.

Methods: Sixty patients with stable COPD were randomized 1:1 to an experimental group $(n=30)$ or a control group $(n=30)$. Subjects in the experimental group trained for four months using an online program which included an animated diagram and video-guided instruction while the control group received conventional patient education on discharge from hospital. Forced expiratory volume, forced expiratory volume in one second $\left(\mathrm{FEV}_{1}\right) /$ forced vital capacity $(\%)$, peak expiratory volume, six-minute walking distance test, and responses to the St George's Respiratory Questionnaire were assessed before and after the intervention.

Results: Patients in the two groups were well matched for demographic and clinical characteristics at baseline. All outcome measures showed significant improvement in the experimental group but not in the control group.

Conclusion: The online training program resulted in improved pulmonary function, exercise capacity, and health status. Therefore, it is strongly recommended that patients with stable COPD be trained with such programs.

Keywords: chronic obstructive pulmonary disease, rehabilitation, adherence, family, nursing intervention, computerized programs

\section{Introduction}

Chronic obstruction pulmonary disease (COPD) is defined as progressive airways obstruction characterized by physical reconditioning and intolerance of exercise. ${ }^{1,2}$ Although there are a variety of drugs which can reduce the symptoms of COPD, there is still no treatment which can restore pulmonary function to a normal predisease status. Therefore, pulmonary rehabilitation has become an important scientifically-based treatment option for maintenance of optimal daily functioning and health-related quality of life. Pulmonary rehabilitation has been shown to improve both exercise tolerance and health status in patients with COPD. ${ }^{3}$ Physical exercise, specifically respiratory muscle training, is a useful nonpharmacological therapy. Although regular exercise has been shown to reduce the most disabling symptoms experienced by patients with $\mathrm{COPD},{ }^{4}$ the benefits of exercise diminish over time if regular exercise is not maintained ${ }^{5,6}$ Clearly, the 
long-term effectiveness of an exercise intervention requires adherence on the part of the patient, which tends to be poor in those with COPD. ${ }^{7}$ Development of shortness of breath on exercise may add to the difficulty experienced by some individuals in terms of self-regulatory efficacy for exercise, and affect their ability to adhere to an exercise program. Exercise intervention programs in patients with COPD need tailoring on an individualized basis to improve the likelihood of consistent participation. In a previous pilot study, patients expressed a wish for greater convenience in recording their daily exercise. ${ }^{8}$ Regular supervision of exercise sessions is necessary to achieve optimal physiologic benefits. Strategies to improve adherence with exercise include praise for accomplishment, skills training, monitoring of the patient's ability to perform exercise, and maintaining regular contact for questions, support, and problem-solving. ${ }^{9}$

Home-based rehabilitation for COPD has been shown to be an effective alternative to pulmonary rehabilitation on an outpatient basis. ${ }^{10}$ Offering different pulmonary rehabilitation settings tailored to individual needs should improve accessibility and uptake of this intervention. ${ }^{10}$ Pulmonary rehabilitation in COPD requires an exercise intervention that is feasible, acceptable, and effective in a variety of settings. In contrast with conventional facility-based pulmonary rehabilitation, home-based exercise programs for patients with COPD can be effective in achieving a reduction in dyspnea and increasing exercise tolerance. ${ }^{11-14}$

Although computer-based programs have diverse applications in health promotion and disease prevention, there is a dearth of literature on the use of Internet technology for home-based management of patients with chronic respiratory disease, ${ }^{15,16}$ and no published studies could be found that incorporated Internet-based rehabilitation programs. This paper describes the effectiveness of an animated diagram and video-guided online rehabilitation program in patients with stable COPD.

Jiangsu Province is the fourth most wealthy area of the People's Republic of China, and most of its residents own computers and have access to the Internet. However, due to rapid economic growth, air pollution is becoming an increasingly serious problem, and the prevalence of COPD is increasing. Therefore, medical research should focus on techniques that are Internet-based.

\section{Materials and methods}

\section{Patients}

An online breathing program for patients with dyspnea was incorporated into the health education program for
COPD provided by nurses at the Respiratory Department of No 1 Yancheng Hospital. The patients were recruited for this study on a volunteer basis. Patients were eligible for inclusion if: they had been diagnosed with COPD according to the 2007 guidelines of the Chinese Society of Respiratory Disease, ${ }^{17}$ their clinical condition was stable at the time of inclusion, there was no history of bronchial asthma, a test for bronchiectasis was negative, no oral glucocorticoid treatment had been taken within the previous three months, and a computer with Internet access was available in the home. All subjects were familiar with logging onto the Internet, navigating their way to a website, and using a computer mouse, and were able to watch an instruction video and graph on the computer screen and listen to an instructional audio with relaxing music. Exclusion criteria were malignancy, cardiac failure, distal arteriopathy, and severe endocrine, hepatic, or renal disease. Written informed consent was obtained from each study participant. Of 72 patients identified initially, 60 were deemed to be eligible for inclusion in the study.

\section{Study design}

We used the formula for two-sample comparison of means to calculate the required sample size: $n_{1}=n_{2}=2\left[\left(\mu_{\alpha}+\mu_{\beta}\right) /(\delta / \sigma)\right]^{2}+1 / 4 \times \mu_{\alpha}^{2},{ }^{18}$ where $n_{1}$ and $n_{2}$ are the sample size required for two groups, $\delta=\mu_{1}-\mu_{2}, \delta$ is the difference between the means, $\mu_{1}$ and $\mu_{2}$ are based on data

Table I Baseline characteristics of DBG and CG

\begin{tabular}{llll}
\hline Variables & DBG & CG & P values \\
\hline Total treated (n) & 29 & 28 & 1.00 \\
Age (range) & $69.4 \pm 3.3$ & $68.8 \pm 1.4$ & 0.87 \\
Female (n) & 8 & 5 & 0.53 \\
BMI & $19.2 \pm 0.4$ & $18.8 \pm 0.2$ & 0.50 \\
Never smokers (n) & 5 & 8 & 0.43 \\
$\quad$ Smokers (n) & 10 & 8 & \\
Former smokers (n) & 14 & 12 & \\
Pack-years & $44.4 \pm 1.7$ & $46.9 \pm 2.3$ & 0.40 \\
FVC & $1.7 \pm 0.0$ & $1.8 \pm 0.0$ & 0.18 \\
FEV & $0.9 \pm 0.1$ & $1.0 \pm 0.0$ & 0.27 \\
FVC (\% pred) & $49.2 \pm 0.5$ & $49.8 \pm 0.7$ & 0.56 \\
FEV,IFVC ratio (\% predicted) & $52.6 \pm 0.5$ & $53.4 \pm 0.4$ & 0.58 \\
PEF & $53.8 \pm 1.1$ & $53.9 \pm 1.1$ & 0.92 \\
6MWDT (m) & $283.4 \pm 1.7$ & $278.8 \pm 2.0$ & 0.09 \\
SGRQ total & $53.9 \pm 0.3$ & $54.5 \pm 0.2$ & 0.10 \\
SGRQ activity & $52.0 \pm 0.3$ & $52.6 \pm 0.3$ & 0.16 \\
SGRQ impact & $46.0 \pm 0.3$ & $44.7 \pm 0.6$ & 0.08 \\
SGRQ symptom & $62.6 \pm 0.2$ & $62.0 \pm 0.3$ & 0.06 \\
\hline
\end{tabular}

Notes: Data are presented as No or mean \pm SD unless otherwise stated. Differences between groups were not significant.

Abbreviations: DBG, dyspnea breathing group; CG, control group; BMI, bodymass index; FVC, forced vital capacity; $\mathrm{FEV}_{1}$, forced expiratory volume in I second; PEF, peak expiratory flow; 6 MWDT, 6-min walk distance test; SGRQ, St George's Respiratory Questionnaire; No, number; SD, standard deviation. 
from a similar rehabilitation program reported by SuQin, ${ }^{19}$ and $\sigma$ is the standard deviation. Using pulmonary function calculations, we estimated that 25 patients would be needed in each study group to detect a clinically important change in pulmonary function with a power of $80 \%$ and $\alpha=0.05$. Assuming a dropout rate of $15 \%,{ }^{20}$ the total sample size increased to 30 . This sample size would also allow us to detect a difference in six-minute walking distance and St George's Respiratory Questionnaire (SGRQ) scores between the two groups with a power of $95 \%$ at a significance level of $5 \%$, assuming a dropout rate of $15 \%$.

Subjects were prospectively randomized $1: 1$ to a dyspnea breathing group or to a control group. Randomization was performed by sealed opaque envelope. Participants in the two study groups were matched for age, gender, body composition, smoking history, pulmonary function, exercise capacity, and health-related quality of life at baseline (see Table 1). Medical treatment prior to enrolment included inhaled salbutamol, ipratropium bromide, and budesonide for patients in both groups, and remained unchanged during the study. Patients in the online dyspnea breathing group undertook a home-based video rehabilitation program comprising four stages of diagrammatic breathing exercises, as demonstrated in Table 2 (showing stage, structure, components, and function) and Table 3 (showing the text and audio guidance for each stage). Each exercise stage lasted

Table 2 Stage, structure, component and function

\begin{tabular}{|c|c|c|c|}
\hline Stage & Structure & Component & Function \\
\hline \multirow[t]{8}{*}{$\begin{array}{l}\text { Pursed-lip breathing } \\
\text { (Figure I) }\end{array}$} & $\begin{array}{l}\text { I. Pursed-lip breathing } \\
\text { video demonstrated } \\
\text { by a respiratory nurse }\end{array}$ & Video & $\begin{array}{l}\text { In this stage, patients would watch the video where a } \\
\text { respiratory nurse demonstrated pursed-lip breathing }\end{array}$ \\
\hline & $\begin{array}{l}\text { 2. Pursed-lip breathing } \\
\text { according to parabola }\end{array}$ & a. Selecting breathing times & $\begin{array}{l}\text { Patients could select } 6-14 \text { breaths/min according to } \\
\text { their exercise tolerance }\end{array}$ \\
\hline & & b. Parabola (Figure 2) & $\begin{array}{l}\text { The parabola was up and down at the ratio of } 1: 2 \text {. } \\
\text { Visual cues were color coded, the elevated parabola } \\
\text { in red for inhaling, and the descending one in black } \\
\text { for exhaling }\end{array}$ \\
\hline & & c. Text guidance & $\begin{array}{l}\text { Text instruction guided patients to perform pursed- } \\
\text { lip breathing. Patients could watch it by clicking on } \\
\text { the image of "Book" }\end{array}$ \\
\hline & & $\begin{array}{l}\text { d. Audio guidance and } \\
\text { relaxing music }\end{array}$ & $\begin{array}{l}\text { Audio instruction guided patients to practice and } \\
\text { Chinese relaxing music could be selected by clicking } \\
\text { on the image of "Speaker" }\end{array}$ \\
\hline & & e. Timer & Recorded the duration of exercise \\
\hline & & f. History record & $\begin{array}{l}\text { The online program would record duration and } \\
\text { breathing times for each respiratory maneuver; } \\
\text { these data would display while "History record" } \\
\text { was clicked }\end{array}$ \\
\hline & $\begin{array}{l}\text { 3. Contact nurse or } \\
\text { other patients }\end{array}$ & & $\begin{array}{l}\text { I. Patient could contact respiratory nurse and raise } \\
\text { questions; the nurse would answer in } 24 \text { hours } \\
\text { 2. Patient could contact other patients and talk about } \\
\text { their practicing experience and health condition }\end{array}$ \\
\hline \multirow[t]{2}{*}{$\begin{array}{l}\text { Deep inhale-slow } \\
\text { blowing - making a fist }\end{array}$} & I. Video & Video & $\begin{array}{l}\text { The video of this stage was a respiratory nurse } \\
\text { demonstrating deep inhale, slow blowing with making } \\
\text { a fist }\end{array}$ \\
\hline & 2. Parabola & $\begin{array}{l}\text { The structures were the same } \\
\text { as the first stage }\end{array}$ & $\begin{array}{l}\text { Functions were the same as the first stage, but } \\
\text { patients could select } 6-10 \text { breaths/min by clicking on } \\
\text { "Select breathing times" }\end{array}$ \\
\hline Deep inhale-holding-slow & I. Video & Video & Displayed this pattern of breathing \\
\hline exhale & $\begin{array}{l}\text { 2. Trapezoid line } \\
\text { (Figure 3) }\end{array}$ & $\begin{array}{l}\text { The structures were the same } \\
\text { as the first stage }\end{array}$ & $\begin{array}{l}\text { I. Displayed a changing direction line. The elevated } \\
\text { part guided patients to inhale, the horizontal part } \\
\text { guided them to hold, and the descending part } \\
\text { guided them to exhale. The ratio of the three } \\
\text { parts was } 1: 1: 2 \\
\text { 2. Patients could select } 6-8 \text { breaths } / \text { min }\end{array}$ \\
\hline Global exercise & Video & $\begin{array}{l}\text { Video: the details described } \\
\text { in Table } 2\end{array}$ & The video included eight steps of global exercises \\
\hline
\end{tabular}


Table 3 Text and audio guidance of each stage

\begin{tabular}{|c|c|}
\hline Stage & Guidance \\
\hline Pursed-lip breathing & $\begin{array}{l}\text { I. Sit or stand with one hand at your chest and the other at your abdomen } \\
\text { 2. Take deep breath and try your best to keep your chest still when you feel your chest slowly bulged } \\
\text { 3. Make your lips in the shape of whistle and slightly lean forward. Blow slowly with your mouth and feel your } \\
\text { abdomen sag } \\
\text { 4. Make a selection from } 6 \text { through I } 4 \text { breaths/min by clicking on "select breathing times." Practice I5-20 minutes per } \\
\text { session and } 2 \text { sessions per day. If dizziness, blurred vision, increased shortness of breath occurs you should select a } \\
\text { large number. Likewise, if you were asymptomatic you should select a smaller number }\end{array}$ \\
\hline $\begin{array}{l}\text { Deep inspiration-slow } \\
\text { blowing - making a fist }\end{array}$ & $\begin{array}{l}\text { I. Sit or stand, make fists and go up at the shoulders level, return to the initial position later, take a deep breath while } \\
\text { going up, blow slowly with whistle while going down } \\
\text { 2. Make a selection from } 6 \text { through } 10 \text { breaths/min by clicking on "select breathing times." The other guidance is the } \\
\text { same as the fourth point of the first stage }\end{array}$ \\
\hline $\begin{array}{l}\text { Deep inhale-holding- } \\
\text { slow exhale }\end{array}$ & $\begin{array}{l}\text { Select one number from } 6 \text { through } 8 \text { breaths/min by clicking on "select breathing times". Inhale deeply through your nose } \\
\text { while the line is elevating, holding breath while it is horizontal, exhale slowly through your mouth while it is descending } \\
\text { The other guidance is the same as the fourth point of the first stage }\end{array}$ \\
\hline Global exercise & $\begin{array}{l}\text { I. There are eight steps in the global exercise: } \\
\text { a. Calm breathing } \\
\text { b. Inhale while standing, exhale while leaning forward } \\
\text { c. Raise left and right hands alternately while taking a deep breath through your nose, put hands slightly at your } \\
\text { abdomen and blow slowly with whistle } \\
\text { d. Move arms out to side at shoulder height while taking deep breath through your nose, put hands back to your side } \\
\text { while blowing slowly with whistle } \\
\text { e. Raise both hands over head while inhaling deeply through your nose, place your hands slightly at your abdomen and } \\
\text { blow slowly with whistle } \\
\text { f. Place hands at shoulder height in front of you while taking a deep breath through your nose, then place your hands } \\
\text { on your abdomen slightly while exhaling slowly with whistle } \\
\text { g. Inhale while holding head, exhale while rotating your head } \\
\text { h. Inhale while raising both arms, exhale while squatting } \\
\text { 2. Make a selection from } 6 \text { through } 10 \text { breaths/min by clicking on "select breathing times". The other guidance is the } \\
\text { same as the fourth point of the first stage }\end{array}$ \\
\hline
\end{tabular}

for one month. Patients in the control group were instructed on the importance of exercise in the same way as the online program but instead by a respiratory nurse at discharge from the hospital. Handouts with pictures of breathing exercises were given to the controls, with advice to perform these exercises for four months.

\section{Dyspnea breathing program}

The breathing program for dyspnea (Figures 1-3) consisted of several elements:

- Patients were instructed to follow the link to the dyspnea breathing program website (http://hljnsys.ycmc.edu. cn/test/user/UserStep4.aspx), sign-in with his or her account, perform the breathing exercises while watching the video and animated diagrams, click the text, receive audio instruction, select relaxing music, contact medical staff and other patients by clicking "Contact Us" in the website, and sign out from the website.

- The program included four stages, ie, pursed-lip breathing, ${ }^{21,22}$ inhaling deeply and exhaling slowly while making a fist, ${ }^{23}$ inhaling deeply, holding slowly, and exhaling, ${ }^{24}$ and general exercise, ${ }^{23,25,26}$ as shown in Tables 2 and 3. The breathing times were selected by the participants according to their level of exercise tolerance.

- The online rehabilitation program was tailored to exercise tolerance on an individualized basis. This was implemented by clicking on "select breathing times" (in the first and second month) and "holding time" (in the fourth month) according to breath retention ability.

- Exercise duration and breathing times were recorded by the online program, so that the patients, their significant others, and nurses could review their progress by clicking on "history record". Patients who had not logging onto the online program regularly would receive a reminder by telephone from the respiratory nurse.

\section{Outcome measures}

Patients in each study group provided outcome data at baseline and at the end of the four-month study period. The respiratory nurses who collected the study data were blinded to patient treatment allocation, as were the data investigators until the analysis was deemed to be complete. 


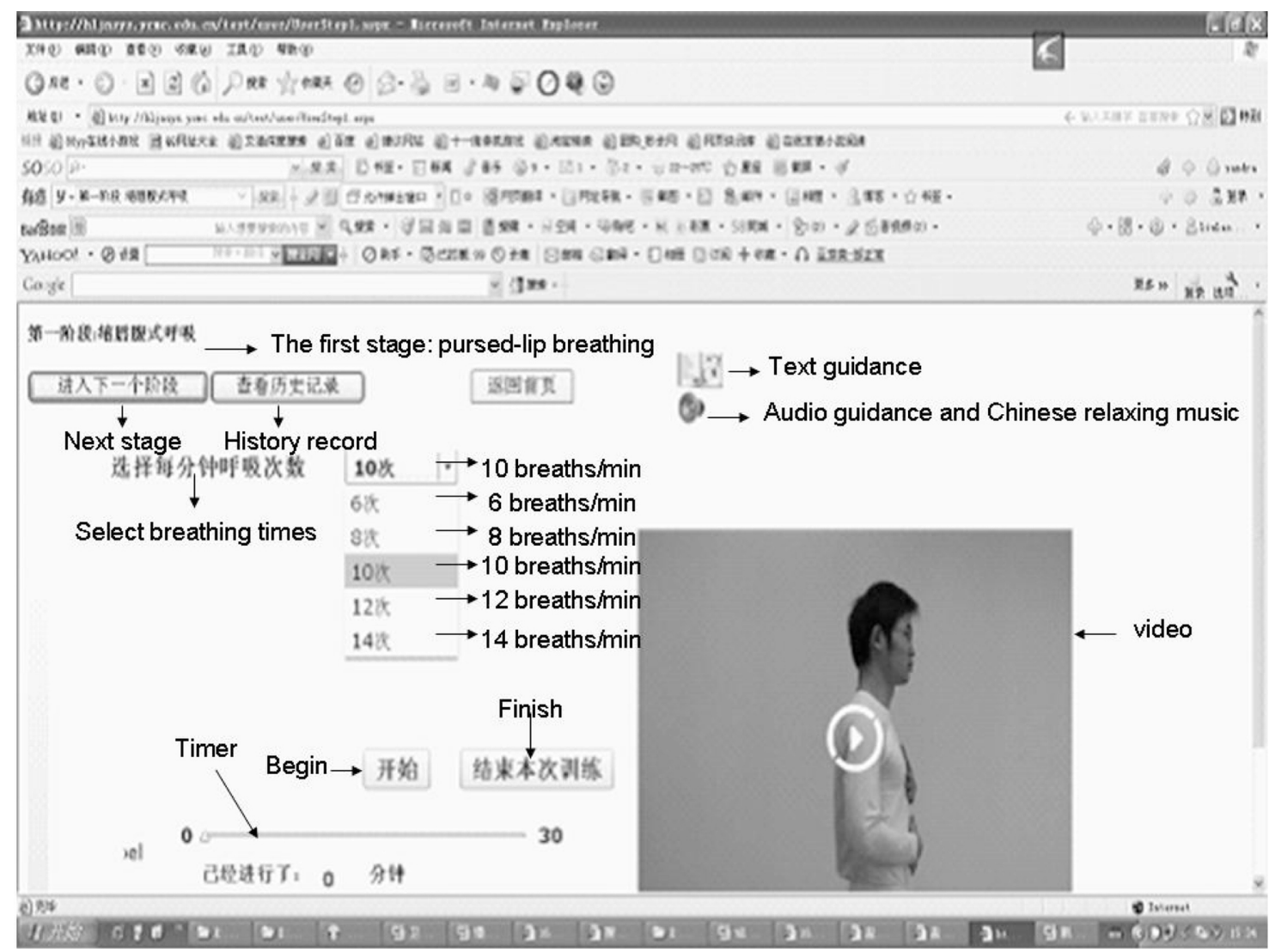

Figure I The first stage.

\section{Pulmonary function tests}

All patients underwent pulmonary function testing ${ }^{27}$ before and after the intervention using the MasterScreen ${ }^{\mathrm{TM}}$ diagnostic system (E Jaeger GmbH, Würzburg, Germany). The pulmonary function tests included forced vital capacity (FVC), the ratio of forced expiratory volume in one second $\left(\mathrm{FEV}_{1}\right) / \mathrm{FVC}$, and peak expiratory flow.

\section{Exercise capacity test}

Patients in both study groups performed the six-minute walking distance tes ${ }^{28}$ along a $30 \mathrm{~m}$ horizontal corridor in the hospital. Each patient received standardized instructions and encouragement to walk up and down the corridor as many times as possible during the allotted time. ${ }^{29}$ At baseline, the patients performed the test three times to avoid learning effects, with 30 minutes of rest between each test. We used data from the best of three tests, and considered a difference in walking distance of $\geq 54 \mathrm{~m}$ as important. ${ }^{30}$

\section{Score of health-related quality of life}

The SGRQ is a 76-item disease-specific respiratory questionnaire measuring health-related quality of life in three domains, ie, symptoms (distress due to respiratory symptoms), activities (effects of impaired mobility), and impact (psychosocial effects of the disease), and provides a total summary score. ${ }^{31}$ Scores range from 0 (no impairment) to 100 (maximal impairment) for each subscale and for the total score. Lower scores indicate better health status, and a change of four points in total score (from a possible 100) is considered clinically meaningful. ${ }^{32}$

\section{Statistical analysis}

The data were analyzed using Statistical Package for Social Sciences version 16.0 software (SPSS Inc, Chicago, IL,

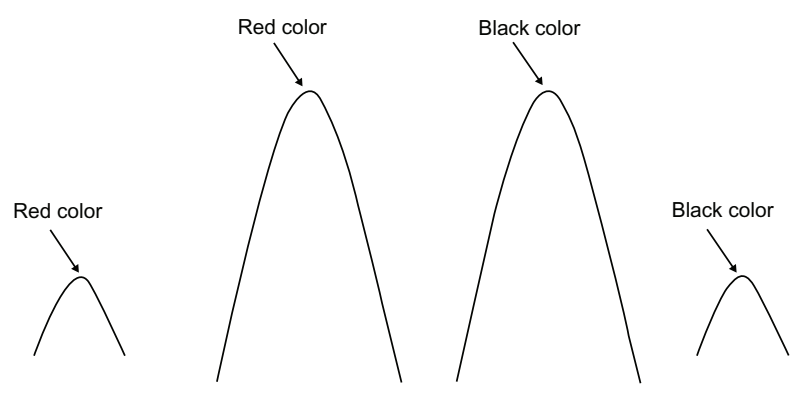

Figure 2 The parabola diagram. 


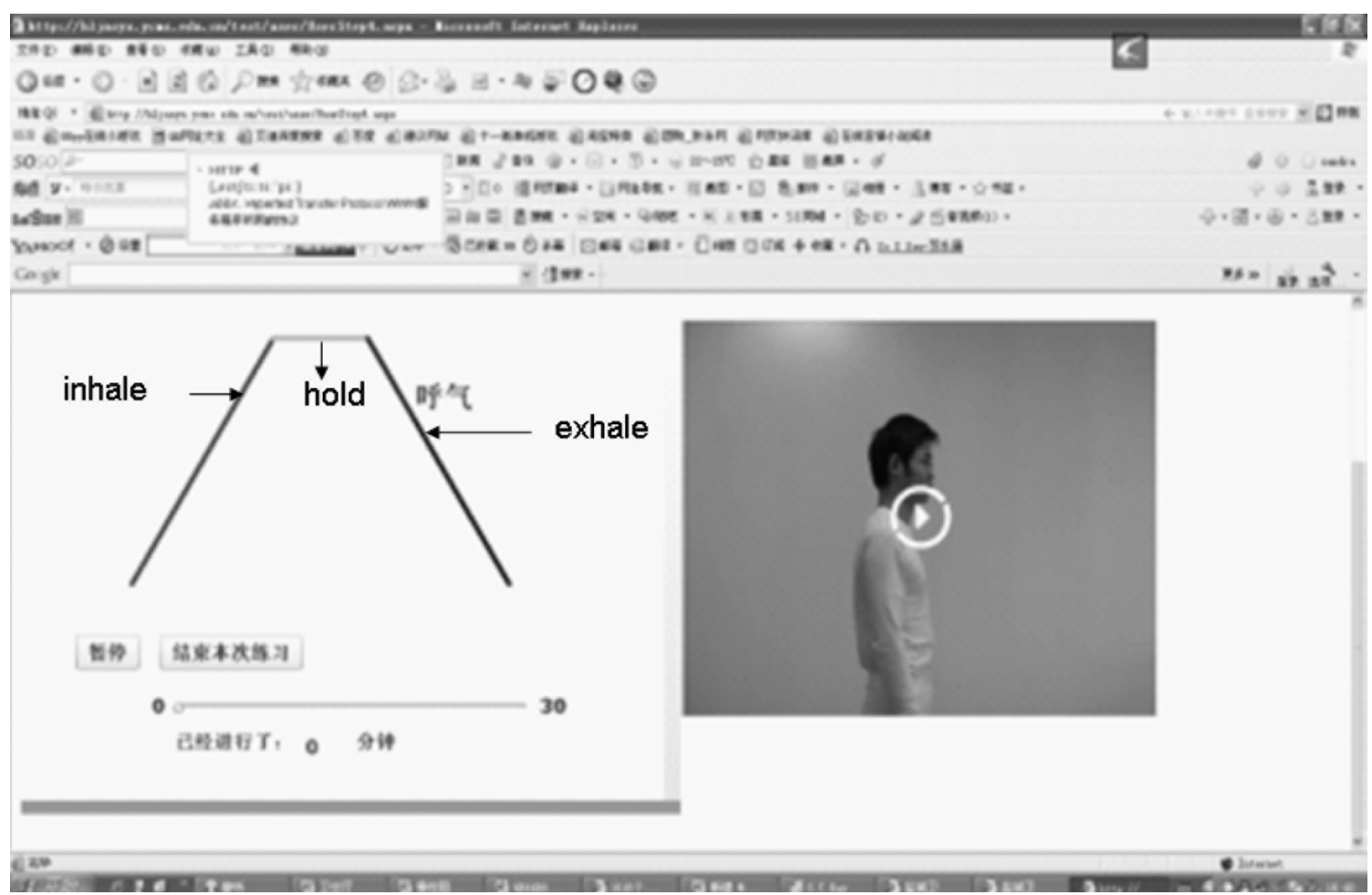

Figure 3 The third stage.

USA). The results are expressed as the mean \pm standard deviation. The number of participants, gender, and smoking history were compared between the two groups using Chi-square and Fisher's Exact tests, and other baseline characteristics were compared using the independent $t$-test. The impact of treatment on pulmonary function, six-minute walking distance test, and SGRQ was evaluated using repeated-measures analysis of variance. $P<0.05$ was considered to be statistically significant, and the approach was two-sided.

\section{Results \\ Baseline}

This randomized trial included 60 subjects with a diagnosis of stable COPD and were recruited between December 2009 and October 2011. The 30 subjects allocated to the breathing program for dyspnea included 19 with stage II disease and 11 with stage III disease..$^{33}$ One patient allocated to the online breathing program for dyspnea died, leaving 29 patients who completed the study. The 30 subjects allocated to the control group included 17 with stage II disease and 13 with stage III disease. One of the control subjects dropped out of the study because of an acute exacerbation, and another died, leaving 28 who completed the study. The demographic and clinical characteristics of the subjects in the two study groups were comparable at baseline (Table 1).
A significant difference in patient adherence was found between the study groups. Twenty-five patients in the dyspnea breathing group practiced regularly using the online program according to the history record, whereas only 14 patients in the control group reported having practiced regularly.

Significant differences were found in FVC, $\mathrm{FEV}_{1}, \mathrm{FVC}(\%$ predicted), $\mathrm{FEV}_{1} / \mathrm{FVC}(\%)$, and peak expiratory flow (Table 4) pulmonary function, six-minute walking distance test, and SGRQ, with increases of $0.6,0.5,5.6,7.5$, and 8.5 , respectively $(P<0.05)$ in the group allocated to the breathing program for dyspnea. Although the control group showed improvements in all domains of pulmonary function, these were not statistically significant. During the rehabilitation phase, the six-minute walking distance increased by $74.6 \mathrm{~m}$ in the dyspnea breathing group and decreased by $5.8 \mathrm{~m}$ in the control group (Table 5); this difference was statistically significant $(P<0.05)$.

The effect of the online dyspnea breathing program on health-related quality of life was assessed using the SGRQ. The two groups were comparable at baseline on the measures of this questionnaire, ie, impact, activity, symptoms, and total score. There was a statistically significant change in these measures in the dyspnea breathing program group $(P<0.05)$ and no change in the control group $(P>0.05$, Tables 1 and 4). 
Table 4 Comparison of treatment effects: pulmonary function, 6MWDT and SGRQ

\begin{tabular}{|c|c|c|c|c|}
\hline \multirow[t]{2}{*}{ Valuables } & \multicolumn{2}{|l|}{ DBG } & \multicolumn{2}{|l|}{ CG } \\
\hline & Baseline & 4 months & Baseline & 4 months \\
\hline FVC & $1.7 \pm 0.0$ & $.3 \pm 0.1^{\#}$ & $1.8 \pm 0.0$ & $1.8 \pm 0.0$ \\
\hline $\mathrm{FEV}_{\text {, }}$ & $0.9 \pm 0.1$ & $1.4 \pm 0.0^{\#}$ & $1.0 \pm 0.0$ & $1.0 \pm 0.0$ \\
\hline VC (\% pred) & $49.2 \pm 0.5$ & $54.8 \pm 0.8^{\#}$ & $49.8 \pm 0.7$ & $50.0 \pm 0.7$ \\
\hline $\mathrm{FEV}_{1} / \mathrm{FVC}(\%)$ & $52.6 \pm 0.5$ & $60.1 \pm 0.7^{\#}$ & $53.4 \pm 0.4$ & $54.1 \pm 0.4$ \\
\hline PEF & $53.8 \pm \mathrm{I} .1$ & $62.3 \pm 0.8^{\#}$ & $53.9 \pm 1.1$ & $54.3 \pm 1.1$ \\
\hline 6MWDT (m) & $283.4 \pm 1.7$ & $358.0 \pm 1.8^{\#}$ & $278.8 \pm 2.0$ & $273 \pm 2.4$ \\
\hline SGRQ activity & $52.0 \pm 0.3$ & $34.5 \pm 0.3^{\#}$ & $52.6 \pm 0.3$ & $51.0 \pm 1.0$ \\
\hline SGRQ impact & $46.0 \pm 0.3$ & $27.1 \pm 0.3^{\#}$ & $44.7 \pm 0.6$ & $4 I .4 \pm 0.8$ \\
\hline SGRQ symptoms & $62.6 \pm 0.2$ & $42.0 \pm 0.3^{\#}$ & $62.0 \pm 0.3$ & $59.6 \pm 1.2$ \\
\hline SGRQ total & $53.9 \pm 0.3$ & $35.3 \pm 0.3^{\#}$ & $54.5 \pm 0.2$ & $53.8 \pm 1.0$ \\
\hline
\end{tabular}

Notes: Values are mean \pm SD unless otherwise stated; $\#<0.05$, comparison of baseline values to follow-up values within groups with the repeated variance measurements analysis.

Abbreviations: DGB, dyspnea breathing group; CG, control group; SGRQ, St George's Respiratory Questionnaire; FVC, forced vital capacity; FEV , forced expiratory volume in I second; PEF, peak expiratory flow; 6MWDT, 6-min walk distance test; m, minutes.

\section{Discussion}

Regular exercise has been shown to reduce the most disabling symptoms in individuals with COPD. The long-term

Table 5 Individual 6MWDT data

\begin{tabular}{|c|c|c|c|}
\hline \multicolumn{2}{|l|}{ DBG } & \multicolumn{2}{|l|}{ CG } \\
\hline Baseline & 4 months & Baseline & 4 months \\
\hline 280 & 360 & 286 & 285 \\
\hline 280 & 362 & 289 & 256 \\
\hline 260 & 359 & 270 & 275 \\
\hline 280 & 362 & 270 & 268 \\
\hline 286 & 358 & 277 & 277 \\
\hline 284 & 357 & 260 & 259 \\
\hline 281 & 362 & 290 & 274 \\
\hline 283 & 357 & 288 & 290 \\
\hline 298 & 360 & 280 & 298 \\
\hline 300 & 362 & 289 & 256 \\
\hline 280 & 359 & 274 & 275 \\
\hline 275 & 362 & 269 & 268 \\
\hline 286 & 358 & 289 & 277 \\
\hline 270 & 357 & 259 & 259 \\
\hline 281 & 362 & 290 & 274 \\
\hline 283 & 357 & 290 & 290 \\
\hline 298 & 360 & 280 & 298 \\
\hline 300 & 362 & 289 & 256 \\
\hline 280 & 359 & 290 & 275 \\
\hline 275 & 362 & 269 & 268 \\
\hline 286 & 358 & 273 & 277 \\
\hline 284 & 357 & 259 & 259 \\
\hline 281 & 362 & 290 & 274 \\
\hline 283 & 357 & 288 & 290 \\
\hline 300 & 362 & 289 & 256 \\
\hline 280 & 359 & 268 & 275 \\
\hline 275 & 362 & 269 & 268 \\
\hline 286 & 358 & 273 & 277 \\
\hline 284 & 310 & & \\
\hline
\end{tabular}

Abbreviations: DBG, dyspnea breathing group; CG, control group; 6MWDT, 6-min walk distance test.
Table 6 Categories and amount of questions

\begin{tabular}{ll}
\hline Category & Amount \\
\hline Benefits of exercise & 10 \\
Complications & 15 \\
Alternative therapy & 8 \\
Diet & 6 \\
Life style & 7 \\
Significant others & 2 \\
Exacerbation of disease & 5 \\
Continuity of exercise & 6 \\
Refers to stable treatment expenses & 7 \\
Total & 66 \\
\hline
\end{tabular}

effectiveness of exercise interventions requires adherence on the part of the patient, which often deteriorates as a result of shortness of breath and dizziness on exercise. Therefore, successful breathing in patients with dyspnea involves maintenance of an exercise program. At the end of this study, FVC, $\mathrm{FEV}_{\mathrm{l}} / \mathrm{FVC}$, peak expiratory flow, sixminute walking distance test, and all domains on the SGRQ as well as the total score showed significant improvement in patients who performed four months of breathing exercises using the online dyspnea program, while no improvement was observed in controls.

There are several possible reasons for the above differences in outcome between patients allocated to the online dyspnea training program and the controls. The synchronous exercise video demonstrated by a respiratory nurse, written instructional text, and audio guidance provided patients with an opportunity to access instructions at any time. The online dyspnea program was beneficial for improving breathing technique by inclusion of pursed-lip breathing, deep inhaling and slow blowing while making a fist, deep inhaling-slow holding-slow exhaling, and global exercise at the beginning of the study, because there was a coach "on the spot" at all times. In this way, the patients could be trained in use of appropriate breathing techniques. Further, the animated diagram guided the patients in practicing breathing patterns designed for patients with stable COPD, making it easy for them to control the depth and frequency of their breathing by following the motion diagram. However, the control patients were not instructed in breathing techniques after discharge in an ongoing way, so it was inevitable that some of them would forget these techniques, making it hard for them to initiate and maintain their exercise program. This could be a reason why some of the control patients abandoned their home-based breathing exercises.

Dyspnea is a critical factor restricting exercise, and plays a significant limiting role in many patients with COPD. ${ }^{34,35}$ Dyspnea affects a patient's ability to adhere with an exer- 
cise program. Because the participants allocated to the online training program for dyspnea had the opportunity to control their breathing frequency and duration of breathholding themselves, rather than this being done by a nurse, a greater training load was achieved during the online program, and was associated with better compliance, resulting in less dyspnea during exercise. In contrast, the controls were instructed by a respiratory nurse on how to perform breathing exercises, and the recommended breathing frequencies and breath-holding times were not always appropriate. Therefore, some patients became fearful about shortness of breath or dizziness, and their adherence with exercise diminished.

Using the online program, the respiratory nurse and patients' significant others could also access and review the "history of exercise", so patients perceived that they were under the supervision of the hospital and family. According to the policy at No 1 Yancheng Hospital, following a hospitalbased dyspnea breathing program, patients are given advice on home exercise at discharge, but very few are provided with any further supervised exercise training. Therefore, patients receiving conventional instruction on breathing exercises are likely to lose motivation after being discharged from hospital. In contrast, in our online intervention group, the convenience of being able to record individualized training results might assist patients to have a sense of accomplishment, such that the perceived benefits would outweigh the barriers to longterm exercise from the patient's point of view.

The online program included 100 classical Chinese music pieces for relaxation which patients could select from, which helped to make exercise sessions a pleasurable experience and be beneficial for patients committing to long-term exercise. ${ }^{36}$ Inclusion of music could also help to alleviate the monotony of exercise and enhance adherence with treatment, whereas doing breathing exercises without music for a long time may lead to boredom and a reluctance to continue.

The breathing program for dyspnea allows for a synchronous communication by clicking the "contact nurse and companions," who are always available online so that individuals can exchange information, provide mutual support, and search for useful services at their convenience.

Nowadays, e-health is becoming increasingly popular. Kroeze et al have reported a systematic review of randomized trials investigating computer-tailored interventions to promote physical activity. They identified 30 studies including adult participants, and concluded that there was little evidence of efficacy for computer-based interventions. Lack of person-to-person contact was considered to be the main reason for the failure of these interventions. ${ }^{37}$

\section{Conclusion}

The results of this controlled study indicate that a four-month online intervention of home-based exercise rehabilitation achieves a clinically significant increase in pulmonary function, exercise tolerance, and quality of life in patients with COPD. However, because of insufficient funding support, this study did not include an investigation of whether the online exercise training program improved arterial blood gases, reduced the frequency of exacerbations, or reduced hospital admissions in patients with COPD. Clearly, this research needs repeating in a larger study population to clarify these questions. Further, we were not able to perform a repeated-measures analysis to compare the effects of the online intervention month by month because of lack of resources to fund pulmonary function tests. The value of such research would be enhanced if it could be subsidized by other organizations or funded by government.

\section{Acknowledgments}

The authors thank those who participated in this study for their time and patience, and appreciate the efforts of Oujiangbaoling Medical Company, Zhejiang Province, in creating the online breathing program for dyspnea (Jiangsu Health Bureau approval number JZ200906) and the Nursing Department of No 1 Yancheng Hospital for approving and supporting this intervention. Thanks are also extended to Linda Honan Pellico, Ronald Milford Tweedie, and Peggy Diller for editing the manuscript.

\section{Disclosure}

The authors report no conflicts of interest in this work.

\section{References}

1. Hamilton AL, Killian KJ, Summers E, Jones NL. Muscle strength, symptom intensity and exercise capacity in patients with cardiorespiratory disorders. Am J Respir Crit Care Med. 1995;152(6 Pt 1):2021-2031.

2. Gosselink R, Troosters T, Decramer M. Peripheral muscle weakness contributes to exercise limitation in COPD. Am J Respir Crit Care Med. 1996;153(3):976-980.

3. Griffiths TL, Burr ML, Campbell IA, et al. Results at 1 year of outpatient multidisciplinary rehabilitation: a randomised controlled trial. Lancet. 2000;355(9201):362-368.

4. Celli BR, MacNee W. Standards for the diagnosis and treatment of patients with COPD: a summary of the ATS/ERS position paper. Eur Respir J. 2004;23(6):932-946.

5. Brooks D, Krip B, Mangovski-Alzamora S, Goldstein RS. The effects of postrehabilitation programmes among individuals with chronic obstructive pulmonary disease. Eur Respir J. 2002;20(1):20-29.

6. Ringbaek T, Brondum E, Martinez G, Thogersen J, Lange P. Long-term effects of 1-year maintenance training on physical functioning and health status in patients with COPD: a randomized controlled study. $J$ Cardiopulm Rehabil Prev. 2010;30(1):47-52. 
7. Garcia-Aymeich J, Farrero E, Félez MA, Izquierdo J, Marrades RM, Antó JM. Risk factors of readmission to hospital for a COPD exacerbation: a prospective study. Thorax. 2003;58(2):100-105.

8. Nguyen HQ, Carrieri-Kohlman V, Rankin SH, Slaughter R, Stulbarg MS. Is Internet-based support for dyspnea self-management in patients with chronic obstructive pulmonary disease possible? Results of a pilot study. Heart Lung. 2005;34(1):51-62.

9. Reardon JZ. COPD and exercise: what's really important? A nursing perspective. COPD. 2007;4(3):283-287.

10. Bourbeau J. Making pulmonary rehabilitation a success in COPD. Swiss Med Wkly. 2010;140:w13067.

11. Alison JA, Samios R, Anderson SD. Evaluation of exercise training in patients with chronic airway obstruction. Phys Ther. 1981;61(9):1273-1277.

12. Busch AJ, McClements JD. Effects of a supervised home exercise program on patients with severe chronic obstructive pulmonary disease. Phys Ther. 1988;68(4):469-474.

13. Wijksta PJ, van der Mark TW, Kraan J, van Altena R, Koëter GH, Postma DS. Effects of home rehabilitation on physical performance in patients with chronic obstructive pulmonary disease (COPD). Eur Respir J. 1996;9(1):104-110.

14. Grosbois JM, Lamblin C, Lemaire B, et al. Long-term benefits of exercise maintenance after outpatient rehabilitation program in patients with chronic obstructive pulmonary disease. J Cardiopulm Rehabil. 1999;19(4):216-225.

15. Silva Junior EP, Esteves GP, Faria AC, Melo PL. An Internet-based system for home monitoring of respiratory muscle disorders. Conf Proc IEEE Eng Med Biol Soc. 2010;2010:5492-5495.

16. Shegog R, Bartholomew LK, Parcel GS, Sockrider MM, Mâsse L, Abramson SL. Impact of a computer-assisted education program on factors related to asthma self-management behavior. $\mathrm{J} \mathrm{Am} \mathrm{Med} \mathrm{Inform}$ Assoc. 2001;8(1):49-61.

17. Chinese Medical Association Respiratory Disease Chronic Obstructive Pulmonary Disease Study Group. Chronic obstructive pulmonary disease diagnosis and treatment guideline (2007 Revision). Zhonghua Jie He He Hu Xi Za Zhi. 2007;30(1):16-19. Chinese.

18. ZhenQiu S, YongYong X. Medical Statistics. 2nd ed. Beijing, China: People's Health Press; 2005.

19. SuQin Z, Yujie Z. Effects of pulmonary rehabilitation and long term oxygen therapy at home on COPD patients. Chinese Journal of Clinical Rehabilitation. 2003;7(18):2603.

20. Puhan MA, Behnke M, Laschke M, et al. Self-administration and standardisation of the chronic respiratory questionnaire: a randomised trial in three German-speaking countries. Respir Med. 2004;98(4):342-350.

21. Spahija J, de Marchie M, Grassino A. Effects of imposed pursed-lips breathing on respiratory mechanics and dyspnea at rest and during exercise in COPD. Chest. 2005;128(2):640-650.
22. Haixia Z, Hongmei M, Haiyan L. Nursing for elderly patients with chronic obstructive pulmonary disease. Chinese Journal Rehabilitation Theory and Practice. 2008;14(11):4901.

23. Xiangwei W. Effects of rehabilitation on aged COPD patients. Internal Medicine of China. 2008;3(5):807-809.

24. Yongjie L, Yingyun C. Effects of breath training pattern "end-inspiratory pause" on respiratory mechanics and arterial blood gas of patients with COPD. JCIM. 2002;8(4):279-283.

25. Hongjun L, Cuiling Y, Zhuangying X. Effects of breathing exercise on pulmonary function and arterial blood gas analysis. Chinese Journal of Clinical Pulmonary Medicine. 2006;11(1):63.

26. Lingjun $Z$, Jijun $Z$. The application status and prospect of breathing exercise in COPD patients. Chinese Nursing Research. 2005;19(3): 478-479.

27. Boqiang C. Diagnosis and assessment for stable COPD. Chinese Practical Geriatrics. 2008;22(3):164-167.

28. ATS Committee on Proficiency Standards for Clinical Pulmonary Function Laboratories: ATS statement: guidelines for the six-minute walk test. Am J Respir Crit Care Med. 2002;166(1):111-117.

29. Guyatt GH, Pugsley SO, Sullivan MJ, et al. Effects of encouragement on walking test performance. Thorax. 1984;39(11):818-822.

30. Redelmeier DA, Bayoumi AM, Goldstein RS, Guyatt GH. Interpreting small differences in functional status: the six minute walk test in chronic lung disease patients. Am J Respir Crit Care Med. 1997;155(4): $1278-1282$.

31. Jones PW, Quirk FH, Baveystock CM, Littlejohns P. A self-complete measure of health status for chronic airflow limitation. The St George's Respiratory Questionnaire. Am Rev Respir Dis. 1992;145(6): 1321-1327.

32. Jones PW. Interpreting thresholds for a clinically significant change in health status in asthma and COPD. Eur Respir J. 2002;19(3):398-404.

33. Baoqiang C. Definition, diagnoses, differential diagnoses, and condition levels. Chin J Tuberc Dis. 2007;30(1):76-79.

34. Maltais F, LeBlanc P, Jobin J, Casaburi R. Peripheral muscle dysfunction in chronic obstructive pulmonary disease. Clin Chest Med. 2000;21(4):665-677.

35. O'Donnell DE. Breathlessness in patients with chronic airflow limitation. Mechanisms and management. Chest. 1994;106(3):904-912.

36. Yueqiu Z, Anqi C, Manghui C. Effect of music on the physiological responses and anxiety levels of patients receiving mechanical ventilation. Chinese Journal of Nursing. 2005;40(7):481-484.

37. Kroeze W, Werkman A, Brug J. A systematic review of randomized trials on the effectiveness of computer-tailored education on physical activity and dietary behaviors. Ann Behav Med. 2006;31(3):205-223.
Patient Preference and Adherence

\section{Publish your work in this journal}

Patient Preference and Adherence is an international, peer-reviewed, open access journal focusing on the growing importance of patient preference and adherence throughout the therapeutic continuum. Patient satisfaction, acceptability, quality of life, compliance, persistence and their role in developing new therapeutic modalities and compounds to

\section{Dovepress}

optimize clinical outcomes for existing disease states are major areas of interest. This journal has been accepted for indexing on PubMed Central. The manuscript management system is completely online and includes a very quick and fair peer-review system. Visit http://www.dovepress.com/ testimonials.php to read real quotes from published authors. 